TLAC/ADD syndrome. Neurology May 1997;48:1435-1439).

A failure to inhibit or delay response, a central executive function, is a major problem in ADHD. These MRI studies suggest that the cerebellum is involved in the frontal-striatal dysfunction postulated in ADHD. Cognitive dysfunction, visuospatial deficits, and mutism are reported in association with cerebellar lesions.

\title{
METHYLPHENIDATE EFFECTS ON EEG AND ADHD
}

The effects of methylphenidate (MPH) on the EEG during baseline and cognitive tasks were evaluated using spectral analysis in 23 boys, aged 9 to 11 , with ADHD, and results were analyzed at the Departments of Psychology, State University of New York, Cortland, NY, and University of Tennessee, Knoxville, TN, and the Kennedy Krieger Institute, Baltimore, MD. Behavioral and performance measures improved with MPH, global effects on the cortical EEG were not observed, but regional changes in the EEG were induced by MPH under taskspecific conditions. The findings support the hypothesis that MPH affects the brainstem and subcortical areas but not cortical function. The value of the EEG as a measure of MPH effectiveness is not supported by these studies. (Swartwood MO, Swartwood JN, Lubar JF et al. Methylphenidate effects on EEG, behavior, and performance in boys with ADHD. Pediatr Neurol April 1998;18:244-250). (Respond: Dr Swartwood, Department of Psychology, State University of New York, Cortland, PO Box 2000, Cortland, NY 13045).

COMMENT. Earlier EEG studies in ADHD subjects, reviewed by the authors, have shown a failure to attenuate alpha activity during mental tasks, decreased beta activity, and increased delta and theta activity. Treatment with MPH may have a normalizing effect, with trends in reduced alpha, increased beta, and reduced overall amplitude. The present study shows EEG changes during MPH treatment, mainly regional and during reading, coding, and visual-motor tasks. Increased beta 1 and beta 2 activity in central and parietal regions of the left hemisphere during visual-motor tasks point toward a normalizing effect of MPH on the EEG. The EEG as a measure of MPH effects in ADHD requires further study.

\section{ASSESSMENT OF ADDERALL IN ADHD}

The time course effects of four doses of $\operatorname{Adderall}^{\circledR}(5,10,15$, and $20 \mathrm{mg})$ were compared to placebo and a single dose of methylphenidate in a randomized, double-blind, crossover study of 30 children with attention deficit hyperactivity disorder (ADHD) treated at the Child Development Center, University of California, Irvine. A capsule was given $\mathrm{AM}$ and time-response and dose-response were assessed every 1.5 hours through the day, using subjective teacher ratings of attention, and objective math test scores at each classroom session. Significant effects were observed by 1.5 hours with doses of Adderal above $5 \mathrm{mg}$, and time of peak effects and duration of action increased with the dose. From 5 to $20 \mathrm{mg}$, the duration of action ranged from 3.5 hrs to 6.4 hrs. Side effects showing a doserelated increase after Adderal adminstration included picking at skin or fingers, appetite loss, and trouble sleeping. Dosage was adjusted in 5 subjects, and 2 elected to withdraw from the trial, one with anorexia ( $20 \mathrm{mg}$ dose) and one with anorexia, "tearful, sad, depressed" and "dull, tired, listless" complaints (10 mg dose). Adderal is recommended in treatment of ADHD. (Swanson JM, Wigal S, Greenhill LL, Cantwell DP et al. Analog classroom assessment of Adderal ${ }^{\circledR}$ in children with ADHD. I Am Acad Child Adolesc Psychiatry May 1998;37:519-526). (Reprints: Dr Swanson, Child Development Center, 19722 MacArthur Blvd, Irvine, CA 92612). 